\title{
Development of A Newton Raphson Symmetrical Component Based Technique for Fault Analysis on Nigerian 330 KV Transmission Lines
}

\author{
Ganiyu Adedayo Ajenikoko ${ }^{1} \quad$ Adebayo Wasiu Eboda $^{1} \quad$ Bolarinwa Samson Adeleke $^{2}$ \\ 1.Department of Electronic and Electrical Engineering, Ladoke Akintola University of Technology, P.M.B, 4000, \\ Ogbomoso, Nigeria \\ 2.Department of Electrical Engineering, The Ibarapa Polytechnic, Eruwa, P.M.B. 1015, Eruwa, Nigeria
}

\begin{abstract}
Fault analysis is one of the basic problems of power system engineering. It plays a significant role in the power system security for supply of stable and economical operations of power systems. This study carried out fault analysis on Nigerian $330 \mathrm{kV}, 28$ bus system using Newton-Raphson analysis and symmetrical components method to determine the voltage magnitude and fault magnitude in the system. Newton-Raphson method was used to calculate the short circuit pre-fault voltages and currents on power system. This was used to check the weak buses that are out of acceptable voltage limit of $\pm 10 \%$. After identifying the buses with problems, a threephase fault on the power network was then calculated using symmetrical component analysis and was simulated using MATLAB to determine the post-fault voltage magnitudes, angles and fault magnitudes of the power network. The pre-fault result showed that buses 13 (New-Haven), 14 (Onitsha) 19 (Jos), 22 (Kano) and 25 (Markurdi) were the buses that fell out of tolerance range of $\pm 10 \%$ and were termed as weak buses. These buses with low voltage values were examined and post-fault calculations were carried out and the results of voltage magnitude and voltage angle were reduced to zeros. The results of pre-fault current magnitude showed that the selected weak buses namely; Makurdi, New-Haven, Kano, Onitsha and Jos have the current magnitude values of 10.4200 p.u, 9.4350 p.u, 8.4501 p.u, 7.5440 p.u and 5.3320 p.u respectively. The results also showed that Makurdi, had the highest fault magnitudes with a value of 25.1006 p.u followed by New-Haven with value of 23.9455 , Kano with value of 22.4917, Jos with value of 21.4686 and Onitsha had the least fault magnitude value of 19.8765 p.u under post-fault condition. More so, it was observed that the voltage on the affected buses was reduced however current magnitudes of these buses when fault occurred were excessively high compared to the pre-fault currents. The result confirmed that symmetrical three phase fault is the most severe kind at the transmission lines. The result also revealed the abnormally high magnitude of current that flows through the Nigerian power network to the point of fault. Therefore, the Nigeria power regulator and policies are required to determine the flow of current regularly during faults occurrences in the power system so as to ensuring improvements in the country power sector. The study therefore recommendations that additional lines should be introduced into the network to assist in the strengthening and reduction of long lines to improve the voltage profile of the network, especially New-Haven, Kano, Onitsha and Markurdi lines. The study will assist the power regulators for selection of circuit breakers and rating of protective switchgears installed in power system to enhance the efficiency of the power supply in Nigeria.
\end{abstract}

Keywords: Fault Analysis, Nigerian Power Network, Newton-Raphson, Symmetrical Components, Three-Phase Fault, Voltage Magnitude, Fault Magnitude.

DOI: $10.7176 / \mathrm{JNSR} / 9-16-02$

Publication date: August $31^{\text {st }} 2019$

\section{I.INTRODUCTION}

Electrical power transmission system is a sequence of interconnected lines that facilitate the bulk movement of electrical energy from a generating station to an electrical substation. In electrical power transmission network, the generating stations are at a relatively far distant from the load centers and are basically interconnected with the help of long transmission lines. Transmission line is essential designed to convey electrical power from the power source over a long distance with minimum losses and with high-voltage three-phase alternating current (AC). This attribute caused the electrical power transmission network to have weak connections between the connected areas $[5,7,9]$.

Electric power transmission lines are characterized by very lengthy transmission lines and therefore are more exposed to the environment. In addition, transmission lines are more prone to faults, which hamper the continuity of electric power supplied, increases the loss of electric power generated, reduced system stability, violation of voltage limits, low system reliability and power system loadability [3]. However, quick detection and classification of this fault using conventional electromechanical devices hastens its clearance and reduces system downtime therefore, improving the security and efficiency of the transmission network [1, 15].

The purpose of fault clearance on transmission network is to generate and supply electrical energy to 
consumers with high reliability and economy [10]. Considering a large power system like Nigeria, the chance of a fault occurring and the disturbance on the system are so enormous that without equipments to remove the faults, the power system will collapse. The management of Nigerian power systems has proven to be more difficult than in the past, this is due to the deregulation in power system which has lead to increase in power competition among others, thus increases the expansion of the transmission network. This deregulation of power sector has witnessed a sudden increase in the demand for electricity with economic consideration as a top priority. The modern deregulated electricity environment has driven utilities to operate the power systems closer to the stability thresholds and to ensure more efficient utilization of transmission networks $[3,9,18]$.

This development has opened a new opportunity for power system operators, however, at the same time the development has put the system under considerable pressure to strike a balance between more profit and fear of possible loss of the system. The deregulation of Nigerian power system has expanded the power system to a certain limit and therefore, there is probability of faults occurrence which requires a new device settings, coordinations and calculations in order to withstand the fault $[2,6]$. A fault will cause currents (short circuit) of high value to flow through the network to the faulted point. Short circuit currents generate heat proportional to the square of their magnitudes and probably damage the insulation of power system devices such as bus bars, cables, circuit breakers and switches. The evaluation of fault occurrence on a power system is therefore significant because the protective devices to be installed on the system depend on the values of the fault currents $[20,21]$.

\section{Overview of Nigeria Transmission Network}

The Nigerian power network consists of a few generating stations mostly sited in remote locations near the raw fuel sources which are usually connected to the load centers by long transmission lines. The transmission capacity of the Nigerian Electricity Transmission system is made up of about 5,523.8 km of $330 \mathrm{KV}$ lines and $6,801.49 \mathrm{~km}$ of $132 \mathrm{KV}$ lines $23 \mathrm{~km}$ of $330 / 132 \mathrm{KV}$ sub-stations and $91 \mathrm{~km}$ of $132 / 33 \mathrm{KV}$ substations [6]. The transmission lines are in radial and are overloaded. The switchgears are obsolete while power transformers have not been maintained for a long time $[6.8,10]$.

A single-line diagram of the Nigeria 330-kV, 28-bus system is as shown in Figure 1 [3]. The $330 \mathrm{kV}$ has 60 transmission line circuits, 8 effective generation stations, 10 load stations and 33 transmission lines. The entire grid system is sectioned into North, South-East and the South-West geographical zones. The North linked the South via one-triple circuit lines between Jebba and Oshogbo, the west connects the East with the help of one transmission line originating from Oshogbo to Benin and one double line from Ikeja to Benin. Part of the problems on the transmission system includes transmission capabilities inefficiency and its radial transmission nature which does not allow for system reliability $[3,10]$.

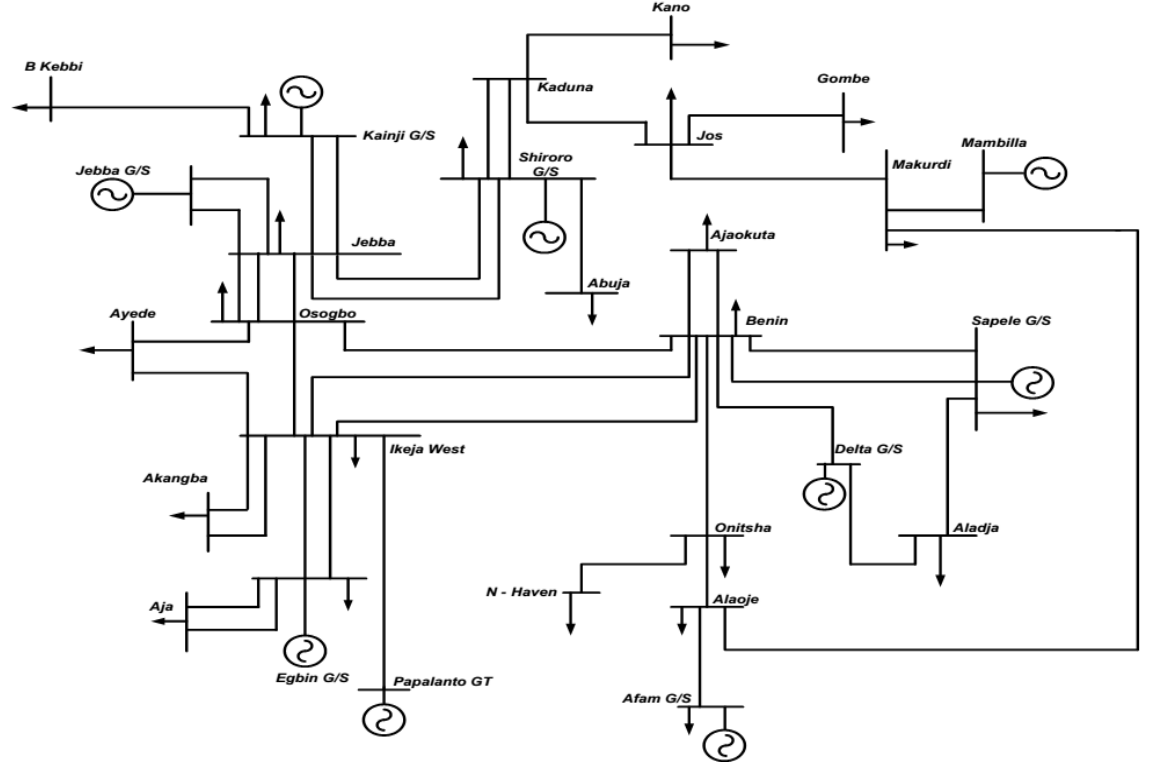

gure 1: Nigerian $330 \mathrm{kV}$ transmission system

\section{III.Power System Fault Analysis}

Power system fault analysis is one of the basic problems in power system engineering. They can be detected and cleared very fast, if the system has a good protection system to avoid damage of the electrical equipment and cause power outage [11]. These faults are grouped into two main types namely: balanced/symmetrical (fault involving one or two phases on the power system) and unbalanced/unsymmetrical faults (fault involving all the 
three phases on the power system). Majority of faults occurring on power systems are unsymmetrical faults, however, the circuit breaker rated MVA breaking capacity is based on three-phase symmetrical faults. The reason is that a three-phase fault produces the greatest fault current and causes the greatest damage to a power system. The only exception to this is a single line to-ground fault occurring very close to a solidly grounded generator's terminal $[11,12]$.

There are many causes of faults in power transmission leading to power outages if not properly managed. These include lightning, insulation aging, heavy winds, trees falling across lines, vehicles colliding with poles, birds, kites, etc. The effects of faults on power system are [13]:

(i) Due to overheating and mechanical forces developed by faults, electrical equipments such as bus-bars, generators and transformers may be damaged.

(ii) The voltage profile of the system may be reduced to unacceptable limits as a result of fault. A frequency drop may lead to instability.

\section{IV.Symmetrical and Non-Symmetrical Faults}

Balanced fault or symmetrical fault is that fault that occurs on the power system which gives rise to symmetrical current or short circuit current [14]. This type of fault occurs when all the three conductors of three phase are brought together simultaneously in a short circuit condition as shown in Figure 2 hence, only positive sequence network is needed to analyze these faults $[14,16]$.

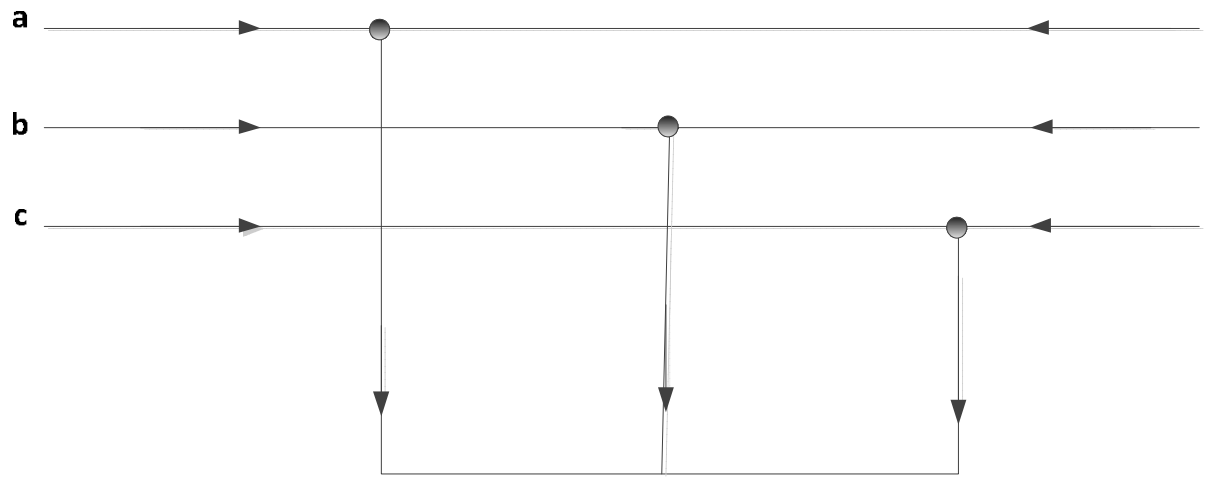

Figure 2: Symmetrical three phase fault

However, majority of faults in power system are unsymmetrical (unbalanced) in nature. These include; single line to ground, double line to ground and line to line faults. Figures 3 to 5 show these types of unsymmetrical faults. In addition, the symmetrical component method is used for unsymmetrical fault analysis on power system in order to calculate and find the line parameters (unsymmetrical fault currents, impedance fault, line currents and voltages) both before and after the fault [14].

When unsymmetrical faults occur on the transmission line, it gives rise to unsymmetrical current. This means that the magnitude of fault currents in the three lines are different having unequal phase displacement. According to [3], every unbalance system of three phase currents and voltages are regarded as composed of three separate sets of balanced vectors. This means that; a balanced three phase sequence current have both a positive and negative phase sequence component while, system of three phase currents equal in magnitude has zero phase displacement and is called zero phase sequence components. The positive, negative and zero sequence components are the symmetrical components of the original unbalanced system $[18,19]$.

Single Line-to-ground faults (SLG): This is the most common type of shunt faults and occurs when one conductor falls to the ground or gets into contacts with the neutral wire. It could also be the result of falling trees in a rainy storm. It accounts for about $70-80 \%$ of faults that occur, which results in interruption of power supply in the country. Figure 3 below shows this type of fault $[4,17]$.

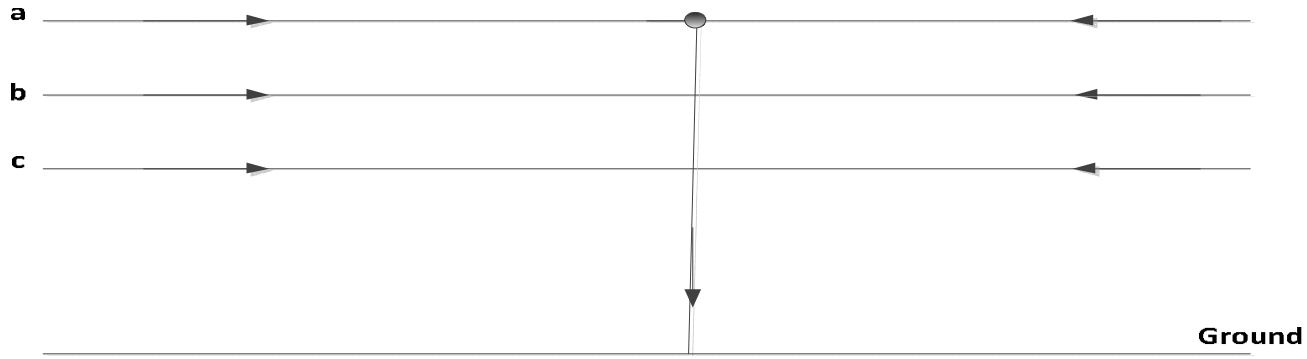

Figure 3: Single line to ground fault 
Line-to-line fault: This is second most occurring type of shunt faults. This is said to occur when two transmission lines are short-circuited. As in the case of a large bird standing on one transmission line and touching the other or if a tree branch happens to fall on top of two power transmission lines. This type of fault can be represented as shown in the Figure $4[8,11]$.

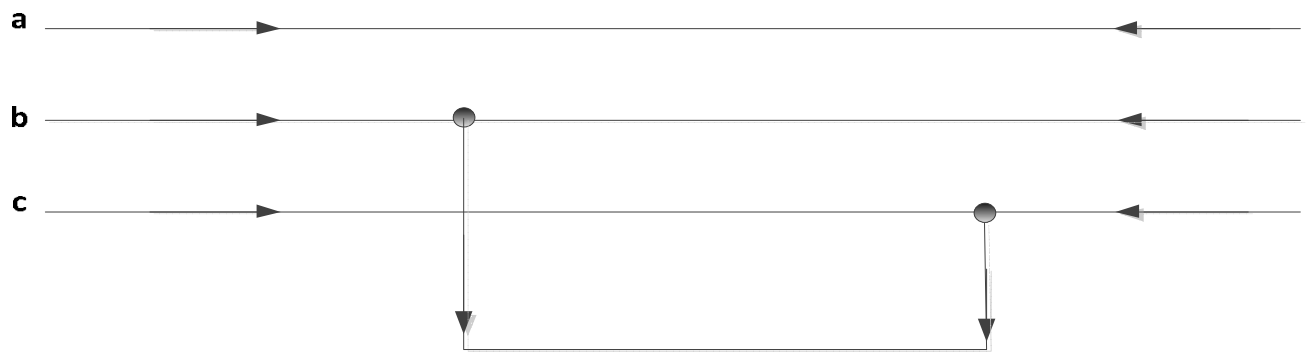

Ground

Figure 4: Line to line fault

Double Line-to-Ground fault (DLG): This occurs as a result of a tree falling on two of the power lines, or other causes. This fault is represented as shown in Figure $5[4,13]$.

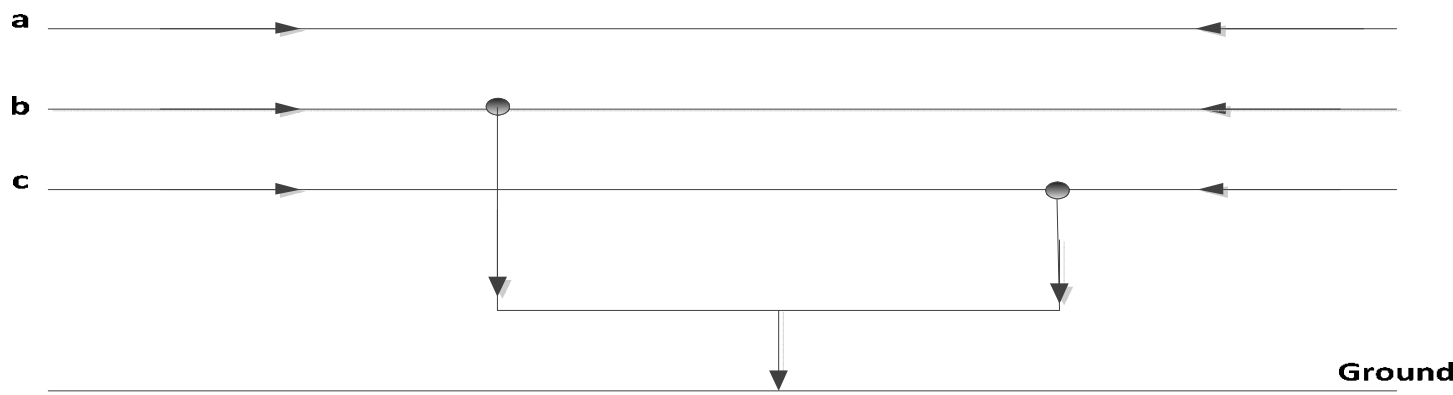

Figure 5: Double line to ground fault

\section{MATERIALS AND METHODS}

This study employed symmetrical component analysis which is a more accurate method of fault analysis on the power system. Because of the balanced nature of short circuit type of fault, the three phases are considered in this study for fault calculation. Newton-Raphson iteration method was adopted to calculate the short circuit prefault voltages and currents on Nigeria $330 \mathrm{kV} 28$-bus system due to its quadratic convergence nature of bus voltages and high accuracies obtained in a few iterations. This was used to check the weak buses that are out of acceptable voltage limit. After identifying the buses, with problem, the fault on the Nigerian $330 \mathrm{kV} 28$-bus network was then calculated using symmetrical component analysis and simulated using MATLAB.

The parameters used for the symmetrical fault calculation in this study are:

i. The protective relays and circuit breakers for the symmetrical fault current and fault impedance were set for the tripping, isolation of the faulted line and for regular operational planning.

ii. The short circuit current was reduced by increasing the impedance on the line between the feeder and point of location of fault in order to avoid damage of equipment.

Others parameters used for the fault calculation is shown in Table 1.

Table 1: Property of the Nigeria $330 \mathrm{kV}$ 28-bus System

\begin{tabular}{|c|c|c|}
\hline S/N & Parameters & Values \\
\hline 1 & Generator Voltage & $(0.99-1.00)$ p.u i.e $\pm 10 \%$ \\
\hline 2 & Transformer Tap Setting & $(0.99-1.00)$ p.u \\
\hline 3 & Total Power Supplied & 3000 to $4000 \mathrm{MW}$ \\
\hline 4 & Base MVA & $100 \mathrm{MVA}$ \\
\hline 5 & Base Voltage & $330 \mathrm{kV}$ \\
\hline 6 & Number of Buses & 28 \\
\hline 7 & Slack Bus & Egbin \\
\hline
\end{tabular}

Under normal conditions, the electrical system is assumed to be operating at its stable pre-fault equilibrium point. The pre-fault current is calculated as: 


$$
I=\frac{(k V A)}{(\sqrt{3} \times \text { Line.current })}
$$

This current will be used to set the protective relay or design a scheme for the protection of the lines against short circuit fault.

The Newton-Raphson load flow method is then applied by beginning with initial guesses of all unknown variables such as voltage magnitude and angles at load buses and voltage angles at generator buses and Taylor's series is written, by ignoring the higher order terms for each of the power balance equations included in the system of equations. At each iteration a Jacobian matrix is formed and solved for the corrections. The Jacobian matrix equation gives the linearized relationship between changes in voltage angle and voltage magnitude as:

$$
\left[\begin{array}{c}
\Delta P \\
\Delta Q
\end{array}\right]=J\left[\begin{array}{c}
\Delta \delta \\
\Delta|V|
\end{array}\right]
$$

Elements of the Jacobian matrix are the partial derivatives which are given as:

$$
J=\left[\begin{array}{ll}
\frac{\partial P}{\partial \delta} & \frac{\partial P}{\partial\left|V_{i}\right|} \\
\frac{\partial Q}{\partial \delta} & \frac{\partial Q}{\partial\left|V_{i}\right|}
\end{array}\right]
$$

The linearized system of equations is solved to determine the next iteration of voltage magnitude and angles as given in equations 4 and 5 :

$$
\begin{aligned}
& \delta_{i}^{(k+1)}=\delta_{i}^{(k)}+\Delta \delta_{i}^{(k)} \\
& \left|V_{i}^{(k+1)}\right|=\left|V_{i}^{(k)}\right|+\Delta\left|V_{i}^{(k)}\right|
\end{aligned}
$$

The process continues until a stopping condition is attained. A common stopping condition is attained when the numbers of mismatch equations are below a specified tolerance.

For the symmetric fault calculation, the admittance bus matrix formed and used in Newton-Raphson load flow analysis was used to obtain the impedance bus matrix for easy fault calculation process. The base impedance of the system can be calculated from these base power and base voltage, as follows,

$$
Z_{b}=\frac{(k V)^{2}}{k V A} O h m s
$$

For simplifying different electrical fault calculations, equation (6) is calculated in per unit values as:

$$
\text { New, } Z_{p . u}=\text { Old }, Z_{p . u} \times \frac{\text { NewbaseMVA }}{\text { OldbasedMVA }}
$$

The symmetrical fault current is calculated as:

$$
I_{k}^{i}=\frac{E}{Z_{k}+Z_{f}}
$$

Also, since the negative and zero sequence are zeros (neglected) for short circuit fault calculation, the symmetrical fault voltage is given as positive sequence which is calculated as:

$$
V_{k}^{i}=E-Z_{k} I_{k}^{i} \quad \text { For }, i=1,2, \ldots \ldots ., n
$$

where

$$
E=\frac{1}{3}\left(E_{r}+E_{y}+E_{b}\right)
$$

where;

$V_{k}^{i}$ is the positive sequence bus phase to neural voltage for bus $\mathrm{k}$

$I_{k}^{i}$ is the positive sequence bus fault current for bus $\mathrm{k}$

$Z_{k}$ is the total positive sequence bus impendence of bus $\mathrm{k}$

$Z_{f}$ is the fault impendence

$E$ is the induced e.m.f under load condition

$\Delta P$ and $\Delta Q$ are the difference between the scheduled and calculated values. 
$\delta_{i}^{(k)}$ is the calculated angle

$\Delta \delta_{i}^{(k)}$ is the change in calculated angle

$\left|V_{i}^{(k+1)}\right|$ is the difference between voltage magnitude at bus $i$

$\left|V_{i}^{(k)}\right|$ is the most recentl voltage magnitude value at bus $i$

$\mathrm{K}$ and $(\mathrm{k}+1)$ denote previous and next iteration respectively.

$\mathrm{K}$ and $(\mathrm{k}+1)$ denote previous and next iteration respectively.

Figure 6 shows the flowcharts for calculating fault currents and voltages for the three-phase fault considered in this study.

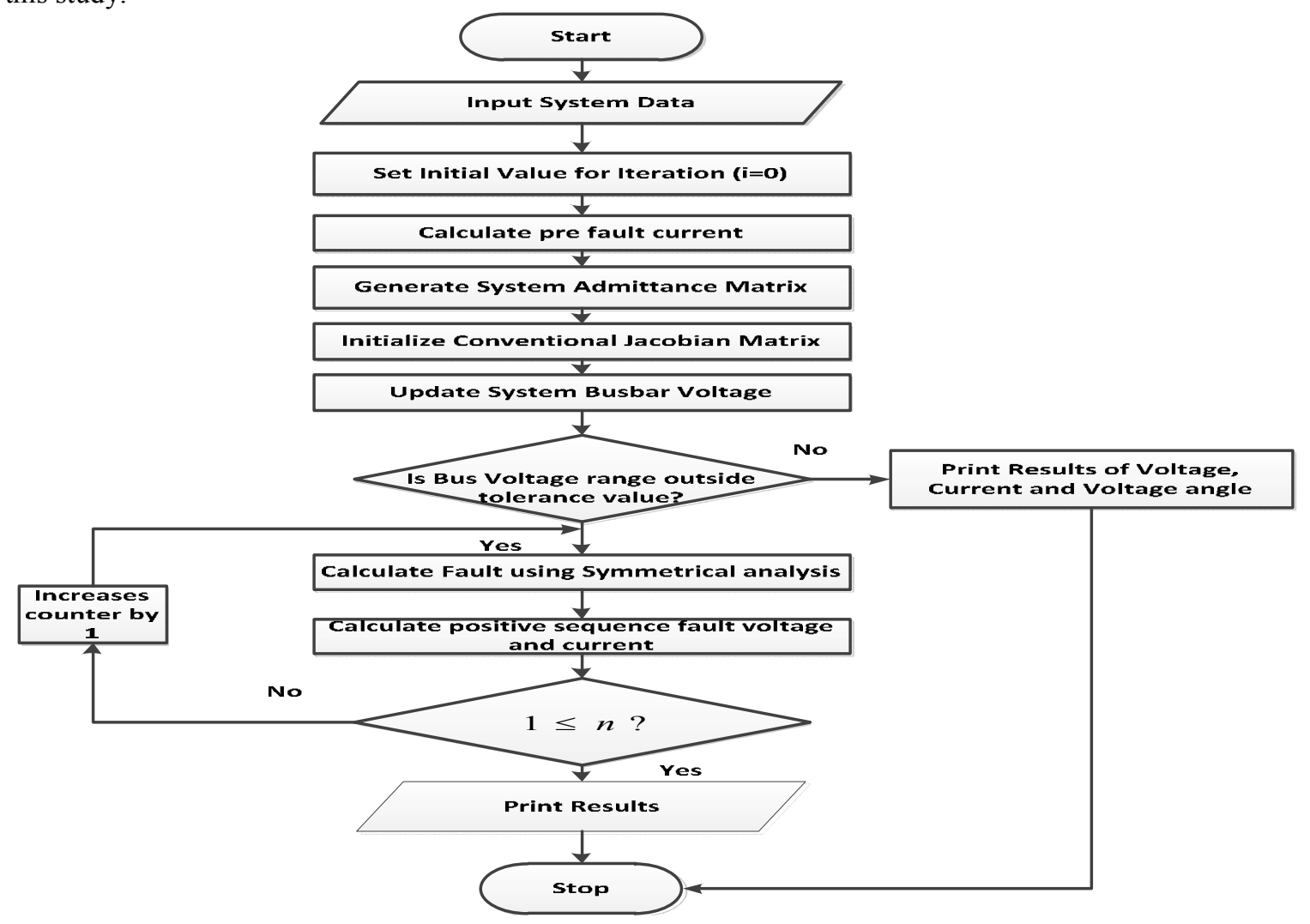

Figure 6: Flowchart for symmetrical three-phase fault calculation

\section{VI.RESULTS AND DISCUSSION}

The results for the fault analysis of Nigeria power network is presented in Table 2 and Table 3 and also in Figures 7 to 10 .

Table 2 shows the result of pre-fault and post-fault calculation of bus fault voltage. The pre-fault result were obtained with load flow analysis using Newton-Raphson to determine the pre fault voltage magnitude and voltage angle at each bus in the power system while the post-fault results were obtained using symmetric fault analysis to determine the post-fault voltage magnitude and voltage angle at each bus in the power system. From the Table, the weak buses with values outside the statutory limit of 0.9900 p.u and 1.1000 p.u. were buses 13 (New-Haven), 14 (Onitsha) 19 (Jos), 22 (Kano) and 25 (Markurdi) with voltage magnitude values 0.9442 p.u, 0.9721 p.u, 0.9681 p.u, 0.8812 p.u and 0.9780 p.u respectively and corresponding voltage angles of -1.0108 p.u, 2.3789 p.u, 8.6210 p.u, -4.2317 p.u and 17.2810 p.u respectively under pre-fault condition. These buses with low voltage values were examined and post-fault calculation was carried out and the results of voltage magnitude and voltage angle were reduced to zeros as showed in Table 2 under post-fault calculation.

Table 3 shows the result of pre-fault and post-fault calculation of bus fault current. The pre-fault result were obtained with load flow analysis using Newton-Raphson to determine the pre fault current magnitude and current angle at each bus in the power system while the post-fault results were obtained using symmetric fault analysis to determine the post-fault current magnitude and current angle at each bus in the power system. The weak buses presented in Table 2 namely; 13 (New-Haven), 14 (Onitsha) 19 (Jos), 22 (Kano) and 25 (Markurdi) have current 
magnitude values of 9.4350 p.u, 7.5440 p.u, 5.3320 p.u, 8.4501 p.u and 10.4200 p.u respectively and corresponding current angles of 0.1017 p.u, 0.1386 p.u, $-0.8691,-0.9654$ and -0.8959 p.u respectively under prefault condition. These buses were examined and post-fault calculation was carried out and the results of current magnitude for these buses were 23.9455 p.u, 19.8765 p.u, 21.4686 p.u, 22.4917 p.u and 25-1006 p.u respectively with corresponding current angle values of -54.6810 p.u, -39.0407 p.u, -52.6971 p.u, -55.9094 p.u and -50.7062 p.u respectively.

Table 2 and Table 3 show that when a fault occurs, the post-fault voltages and current are different from pre-fault voltage and current. While the voltage on the affected phase is reduced, the current rises tremendously.

Figure 7 shows the variation in magnitude of the fault voltage for the weak buses with pre-fault condition. From the graph bus (25) which is Makurdi, had the highest voltage drop with value of 0.9780 p.u because of its distance from the grid, followed by Onitsha, Jos, New-Haven and kano with voltage magnitude values of 0.9721 p.u, 0.9681 p.u, 0.9442 p.u and 0.8812 p.u respectively. Most of these buses are located at the areas where load consumption is high. This, coupled with the fact that most lines connecting these buses are very long transmission lines, thus resulting in low voltages of these buses.

Table 2: Bus fault voltages result of Nigerian $330 \mathrm{kV} 28$-bus system

\begin{tabular}{|c|c|c|c|c|c|c|}
\hline \multirow[b]{3}{*}{ Bus No } & \multirow[b]{3}{*}{ Bus Name } & \multirow[b]{3}{*}{ Bus Type } & \multicolumn{2}{|c|}{ Pre-Fault Calculation } & \multicolumn{2}{|c|}{ Post-Fault Calculation } \\
\hline & & & Voltage & Voltage & Voltage & Voltage \\
\hline & & & $\begin{array}{l}\text { Magnitude } \\
\text { (p.u) }\end{array}$ & $\begin{array}{l}\text { Angle } \\
\text { (deg) }\end{array}$ & $\begin{array}{l}\text { Magnitude } \\
\text { (p.u) }\end{array}$ & $\begin{array}{l}\text { Angle } \\
\text { (deg) }\end{array}$ \\
\hline 1 & Egbin & Swing & 1.0500 & 0.0000 & 0.0589 & 17.9768 \\
\hline 2 & Delta & PV & 1.0500 & 10.8712 & 0.4918 & 24.9485 \\
\hline 3 & Aja & PQ & 1.0450 & -0.2871 & 0.0865 & 20.9904 \\
\hline 4 & Akangba & PQ & 1.0154 & 0.4494 & 0.0158 & 45.9863 \\
\hline 5 & Ikeja-West & PQ & 1.0128 & 0.7268 & 0.6866 & 15.4733 \\
\hline 6 & Ajaokuta & PQ & 1.0304 & 5.0071 & 0.4645 & 24.6068 \\
\hline 7 & Aladja & PQ & 1.0121 & 9.3831 & 0.4599 & 25.2501 \\
\hline 8 & Bennin & PQ & 1.0017 & 5.3945 & 0.4365 & 24.9947 \\
\hline 9 & Ayede & PQ & 0.9933 & 1.7568 & 0.6041 & 15.8911 \\
\hline 10 & Oshogbo & PQ & 1.0232 & 7.3006 & 0.3918 & 24.7250 \\
\hline 11 & Afam & PV & 1.0500 & 8.0994 & 0.7776 & 21.1925 \\
\hline 12 & Alaoji & PQ & 1.0144 & 8.0613 & 0.7591 & 20.4913 \\
\hline 13 & New-Haven & PQ & 0.9442 & -1.0108 & 0.0000 & 0.0000 \\
\hline 14 & Onitsha & PQ & 0.9721 & 2.3789 & 0.0000 & 0.0000 \\
\hline 15 & Birnin-Kebbi & PQ & 1.0162 & 10.2111 & 0.5817 & 29.5048 \\
\hline 16 & Gombe & PQ & 0.9914 & 1.2244 & 0.7616 & 17.0914 \\
\hline 17 & Jebba & PQ & 1.0500 & $11 . .5675$ & 0.4957 & 30.3065 \\
\hline 18 & Jebba_GS & PV & 1.0500 & 12.8015 & 0.4985 & 30.1126 \\
\hline 19 & Jos & PQ & 0.9681 & 8.6210 & 0.0000 & 0.0000 \\
\hline 20 & Kaduna & PQ & 1.0265 & 4.6161 & 0.6950 & 21.0784 \\
\hline 21 & Kainji & PV & 1.0500 & 14.7516 & 0.5066 & 37.2660 \\
\hline 22 & Kano & PQ & 0.8812 & -4.2317 & 0.0000 & 0.0000 \\
\hline 23 & Shiroro & PV & 1.0500 & 6.0417 & 0.6719 & 24.0810 \\
\hline 24 & Sapele & PV & 1.0500 & 7.3086 & 0.4330 & 26.2562 \\
\hline 25 & Makurdi & PQ & 0.9780 & 17.2810 & 0.0000 & 0.0000 \\
\hline 26 & Abuja & PQ & 1.0185 & -3.4560 & 0.6965 & 19.8595 \\
\hline 27 & Manbila & PV & 1.0500 & 41.7800 & 0.8866 & 47.3579 \\
\hline 28 & Papalanto & PV & 1.0500 & 5.4870 & 0.1043 & 11.9453 \\
\hline
\end{tabular}


Table 3: Bus fault current result of Nigerian $330 \mathrm{kV} 28$-bus system

\begin{tabular}{|c|c|c|c|c|c|c|}
\hline \multirow[b]{3}{*}{ Bus No } & \multirow[b]{3}{*}{ Bus Name } & \multirow[b]{3}{*}{ Bus Type } & \multicolumn{2}{|c|}{ Pre-Fault Calculation } & \multicolumn{2}{|c|}{ Post- Fault Calculation } \\
\hline & & & Current & Current & Current & Current \\
\hline & & & $\begin{array}{l}\text { Magnitude } \\
\text { (p.u) }\end{array}$ & $\begin{array}{l}\text { Angle } \\
\text { (deg) }\end{array}$ & $\begin{array}{l}\text { Magnitude } \\
\text { (p.u) }\end{array}$ & $\begin{array}{l}\text { Angle } \\
\text { (deg) }\end{array}$ \\
\hline 1 & Egbin & Swing & 0.5442 & 0.0000 & 3.2822 & -62.8614 \\
\hline 2 & Delta & PV & 0.4680 & 0.02565 & 2.7692 & -57.8165 \\
\hline 3 & Aja & $P Q$ & 0.2870 & -0.0815 & 1.9758 & -33.1597 \\
\hline 4 & Akangba & PQ & 0.3561 & -0.1126 & 1.1974 & -53.7381 \\
\hline 5 & Ikeja-West & PQ & 1.7100 & -0.0985 & 1.7235 & 38.9557 \\
\hline 6 & Ajaokuta & $P Q$ & 0.7861 & 0.0929 & 0.9575 & 17.1493 \\
\hline 7 & Aladja & $P Q$ & 0.4780 & 0.1341 & 2.1718 & 35.7645 \\
\hline 8 & Bennin & PQ & 2.9350 & 0.0299 & 5.2087 & 34.9647 \\
\hline 9 & Ayede & $P Q$ & 0.9710 & -0.1643 & 1.2981 & 32.6703 \\
\hline 10 & Oshogbo & $P Q$ & 2.1870 & -0.1503 & 4.7596 & -56.7140 \\
\hline 11 & Afam & PV & 0.1240 & 0.3143 & 1.6929 & -18.6891 \\
\hline 12 & Alaoji & PQ & 0.6671 & 0.2917 & 0.9987 & 33.5607 \\
\hline 13 & New-Haven & $\mathbf{P Q}$ & 9.4350 & 0.1017 & 23.9455 & -54.6810 \\
\hline 14 & Onitsha & $\mathbf{P Q}$ & 7.5440 & 0.1386 & 19.8765 & -39.0407 \\
\hline 15 & Birnin-Kebbi & $P Q$ & 0.7100 & -0.1449 & 3.9487 & -50.2371 \\
\hline 16 & Gombe & PQ & 0.0165 & -0.9738 & 2.9417 & -43.5485 \\
\hline 17 & Jebba & PQ & 1.8650 & -0.1113 & 4.8199 & -27.6539 \\
\hline 18 & Jebba_GS & PV & 0.0220 & -0.1329 & 1.7896 & 19.9547 \\
\hline 19 & Jos & $\mathbf{P Q}$ & 5.3320 & -0.8691 & 21.4686 & -52.6971 \\
\hline 20 & Kaduna & PQ & 0.9950 & -0.6943 & 1.9976 & 20.6147 \\
\hline 21 & Kainji & PV & 1.4760 & -0.0784 & 4.0357 & -20.8453 \\
\hline 22 & Kano & $\mathbf{P Q}$ & 8.4501 & -0.9654 & 22.4917 & -55.9094 \\
\hline 23 & Shiroro & PV & 1.8813 & -0.5467 & 2.9651 & -67.9546 \\
\hline 24 & Sapele & PV & 0.4570 & 0.0353 & 1.9542 & 32.7799 \\
\hline 25 & Makurdi & PQ & 10.4200 & -0.8959 & 25.1006 & -50.7062 \\
\hline 26 & Abuja & PQ & 0.2103 & -5.9164 & 5.4783 & 25.3794 \\
\hline 27 & Manbila & PV & 0.1510 & 0.1914 & 2.0629 & 37.3379 \\
\hline 28 & Papalanto & PV & 0.0726 & 0.0899 & 6.1023 & 31.5493 \\
\hline
\end{tabular}

Figure 8 shows the relationship between bus names and pre-fault current magnitude of the selected weak buses under pre-fault condition. Bus (25) which is Makurdi, had the highest current magnitude with value of 10.4200 p.u followed by New-Haven, Kano, Onitsha and Jos with values of 9.4350 p.u, 8.4501 p.u, 7.5440 p.u and 5.3320 p.u respectively due to the fact that most lines connecting these buses are very long transmission lines, resulting in high current in these buses.

Figure 9 depicts the relationship between bus name and post-fault current magnitude of the selected weak buses under post-fault condition. Bus (25) which is Makurdi, had the highest current magnitude with value of 25.1006 p.u followed by New-Haven with value of 23.9455 , Kano with value of 22.4917 , Jos with value of 21.4686 and Onitsha had the least current magnitude value of 19.8765 .

In addition, Figure 10 shows the relationship between bus names and pre-fault and post-fault current magnitudes of the selected weak buses. It was observed that current magnitudes of these buses when fault occurs are excessively high compared to the pre-fault currents. Currents of abnormally high magnitudes flow through the network to the point of fault. 


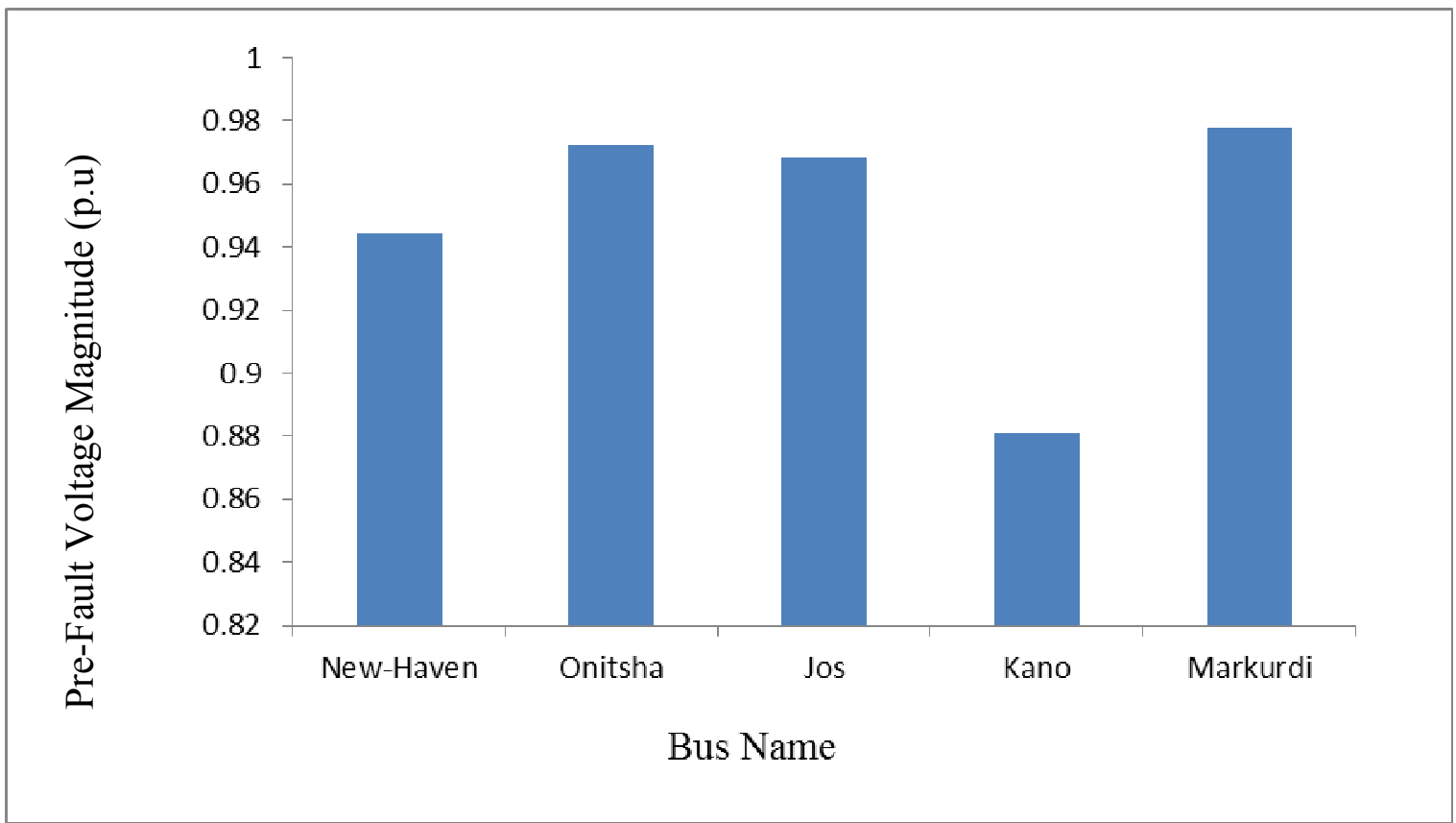

Figure 7: Pre-fault voltage magnitude versus selected bus name

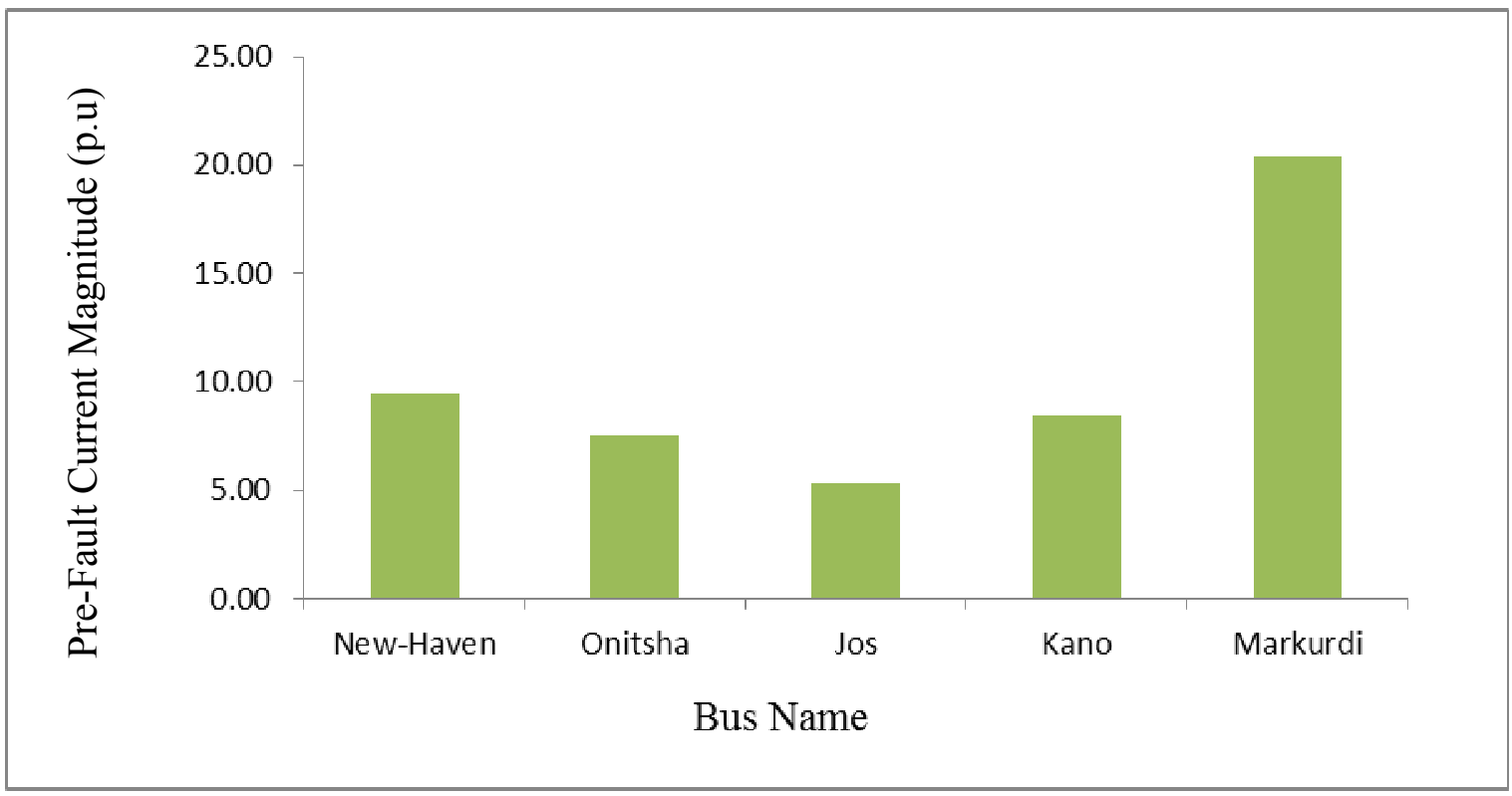

Figure 8: Pre-fault Current magnitude versus selected bus name 


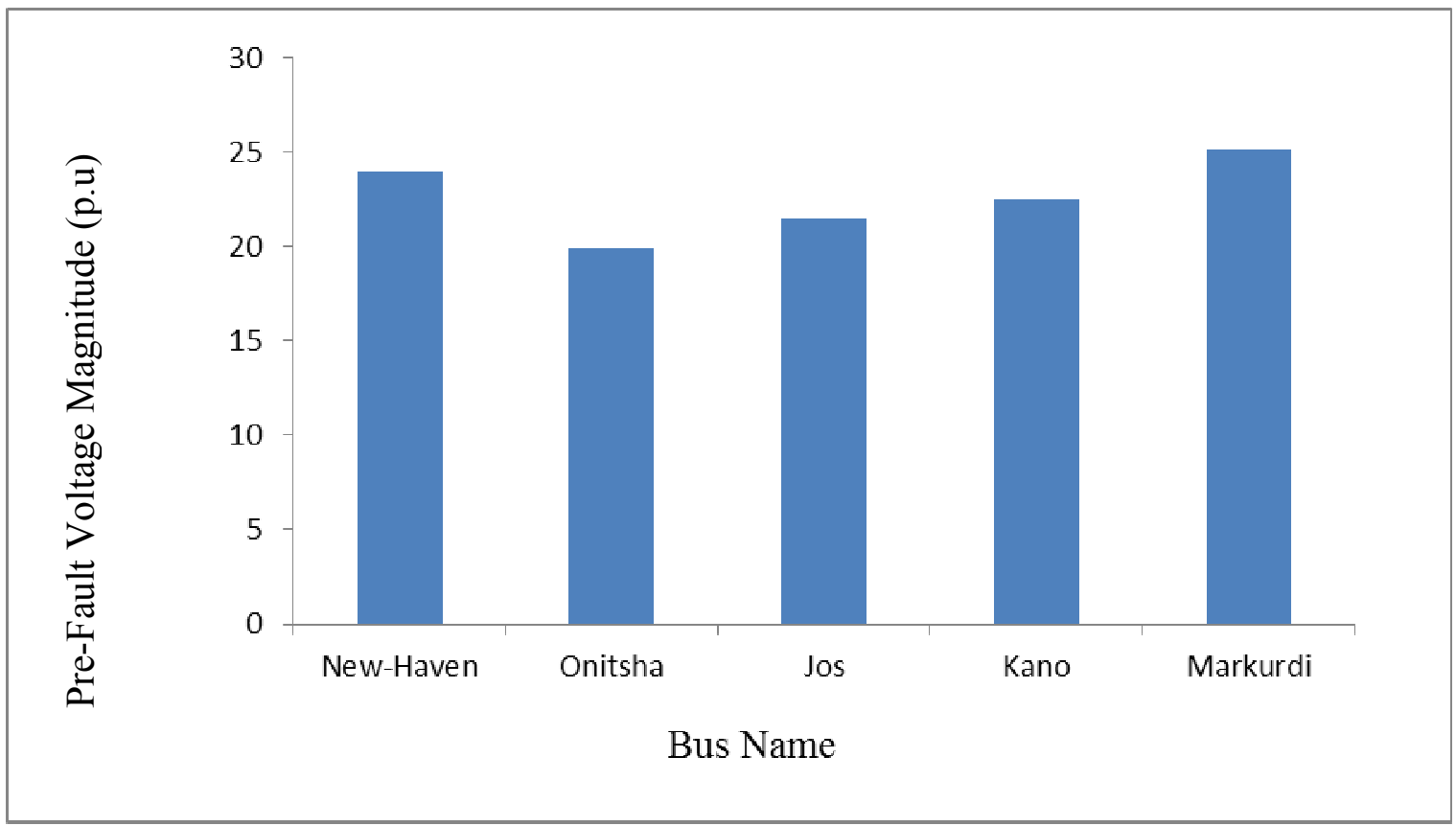

Figure 9: Post-fault current magnitude versus selected bus name

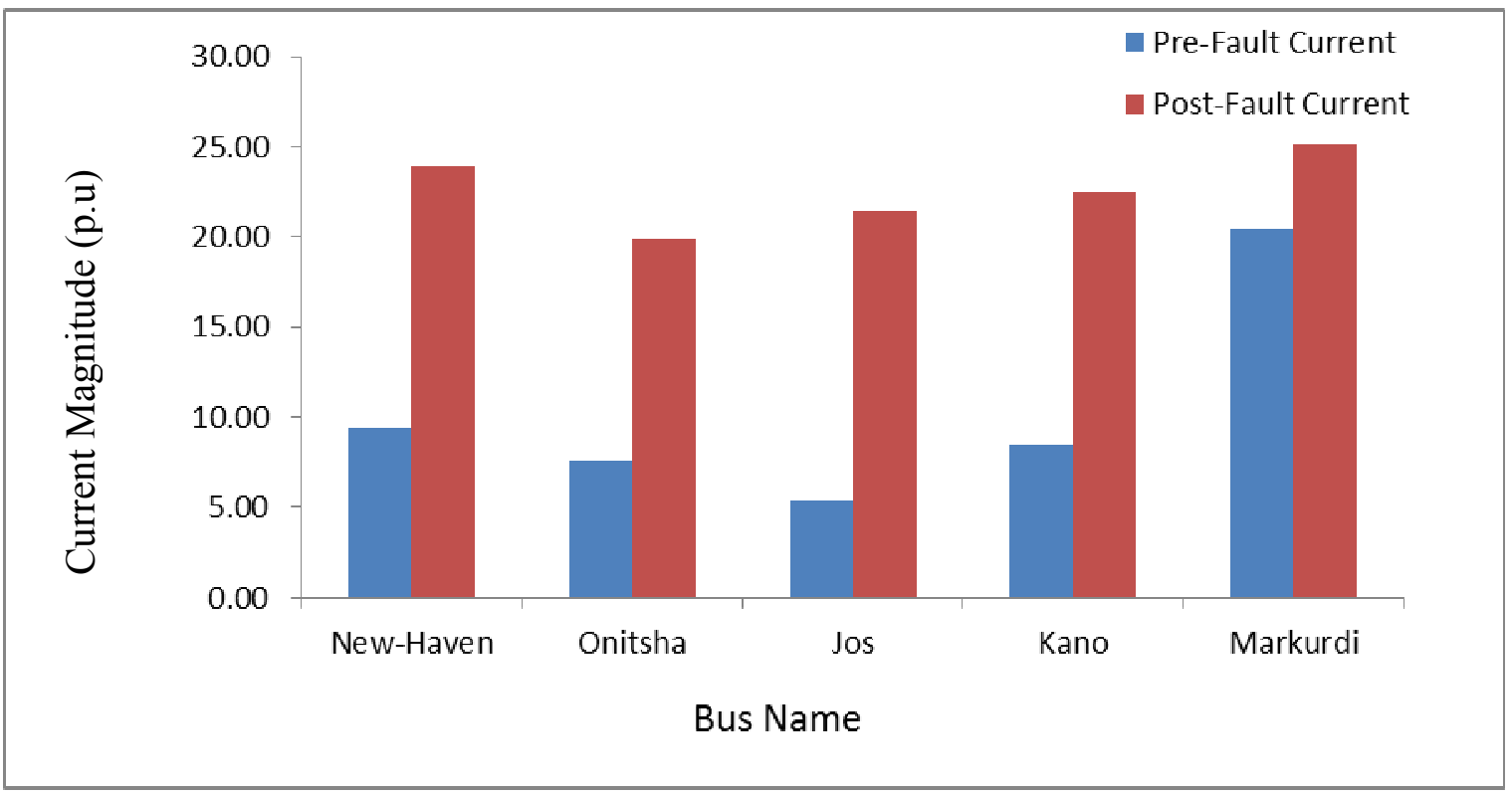

Figure 10: Comparison between pre-fault and post-fault current magnitude versus selected bus name

\section{CONCLUSION}

In this study fault analysis was carried out on Nigeria power system using Newton-Raphson analysis and symmetrical components method with the intent of determining the fault conditions of the Nigeria power network so as to suggest possible means of ensuring improvements in the country power sector. The load flow analysis was carried out using the Newton-Raphson load flow method. This analysis determined the pre-fault voltage magnitude and angle, and current magnitude and current angle in p.u at each bus in the power system to determine the buses that were out of tolerance range of $\pm 10 \%$. After the load flow analysis, a three-phase fault using symmetrical component was simulated on the power system at these weak buses, the post-fault voltage magnitude and angle, current magnitude and current angle were calculated. The pre-fault result showed that buses 13 (New-Haven), 14 (Onitsha) 19 (Jos), 22 (Kano) and 25 (Markurdi) were the buses that fell out of tolerance range of $\pm 10 \%$ and were termed weak buses. These buses with low voltage values were examined and post-fault calculation was carried out and the results of voltage magnitude and voltage angle were reduced to zeros. The post-fault voltages and current were different from pre-fault voltage and current. The voltage on the affected buses was reduced however, the current at these buses rose tremendously, coupled with the fact that 
most lines connecting these buses were very long transmission lines, resulting in high current and low voltage in these buses.

The continuous expansion of the Nigeria power sectors will cause fault to occur in the network. Appropriate policies are required to determine the flow of current regularly when three-phase faults occur in the power system so as to ensure improvements in the country power sector. The study will assist the power regulators for selection of circuit breakers and rating of protective switchgears installed in power system.

\section{RECOMMENDATIONS}

To improve on the availability and stability of Nigeria power system the following recommendations were suggested.

i. Use of high speed circuit breaker. The quicker a breaker operates, the faster the fault is removed from the system and better is the tendency of the system to restore to normal operating conditions.

ii. The use of digital system in tracking fault will reduce the time clearing time of fault.

iii. All fault equipments or component such as cross arms, cracked insulators, circuit breaker should be replaced on time.

iv. Proper vegetation management to reduce the problem of short-circuits and earth fault should be provided.

Furthermore, additional lines should be introduced into the network to assist in the strengthening and reduction of long lines to improve the voltage profile of the network, especially New-Haven, Kano, Onitsha and Markurdi lines. In addition, planned and routine maintenance should be carried out on the network to reduce the incidence of voltage collapse.

\section{IX.REFERENCES}

[1] Ademola, A. G. (2016). Evaluation and mitigation of technical losses on power lines: a case study of Nigeria 330-kv network. A Thesis Submitted to the Department of Electrical And Information Engineering And To The School Of Postgraduate Studies in Partial Fulfilment of the Requirements for the Award of Doctor of Philosophy (Ph.D) in Electrical and Electronics Engineering. 1-300.

[2] Ademola, A., Awosope C. O. A. and Awelewa, A, A. (2016). The use of three phase fault analysis for rating circuit breaker on Nigeria $330 \mathrm{kV}$ transmission lines. Journal of Engineering and Applied and Sciences, 11(12): 2612-2622.

[3] Adepoju, G. A., Tijani, M. A., Sanusi, M. A and Olatunji, D. O. (2013). Three-phase fault currents evaluation for Nigerian 28-bus $330 \mathrm{kv}$ transmission system. International Journal of Engineering Research and Applications, 3 (2): 125-132.

[4] Agbesi, I. K. and Okai, F. A. (2016). Automatic fault detection and location in power transmission lines using GSM technology. International Journal of Advance Research In Science and Engineering. 5(1): 193-207.

[5] Ajenikoko, G.A., Eboda, A.W., Adigun, O., Ahmed Olayinka, A., Oni, S. O. and Adelowo, L. (2018). Analysis of power sector performance: Nigeria as a case study. Mathematical Theory and Modeling, 8(8) 64-71.

[6] Ajenikoko, G. A and Ogunwuyi, O. J. (2015). A model for assessment of power system outages on Nigerian transmission network. The International Journal of Engineering and Science, 4 (4): 73-80.

[7] Ayamolowo, O. J., Oladipo, F. and Elutunji,B. (2017). Fault analysis of injection substation using symmetrical component method a case study of Mofor injection substation, Delta state, Nigeria. American Journal of Engineering Research, 6 (10):83-97.

[8] Mbamaluikem, P. O. and Awelewa, A. A. (2018). An Artificial Neural Network-Based intelligent fault classification system for the 33-kV Nigeria transmission line. International Journal of Applied Engineering Research, 13 (2): 1274-1285.

[9] Obuma, K. O. (2015). Application of artificial neural network for enhanced power system protection in the Nigerian 330kV network. A Thesis Submitted in Partial Fulfilment for the Requirement of the Award of M.ENG (Power Systems Engineering). 1-100.

[10] Ogar, V.N., Abara, D.N. and Akpama, E. J. (2017). Symmetrical and Unsymmetrical Faults Analysis: using Nigeria 330-KV grid as case study. IEEE Journal. 1-7.

[11] Ogboh V. C and Madueme, T. C. (2015): Investigation of faults on the Nigerian power system transmission line using Artificial Neural Network. International Journal of Research in Management, Science \& Technology, 3 (4): 87-95.

[12] Ogbuefi, U. C. and Madueme, T. C. (2015). A power flow analysis of the Nigerian $330 \mathrm{kV}$ electric power system. IOSR Journal of Electrical and Electronics Engineering, 10 (1): 46-57.

[13] Oladimeji, J. A. (2017). Fault analysis of injection substation using symmetrical component method and 
validation of results using MATLAB: a case study of Mofor injection substation, Delta state, Nigeria. International Journal of Advanced Research in Electrical, Electronics and Instrumentation Engineering, 6 (4): 1-18.

[14] Oluleke O. Babayomi1 and Peter O. Oluseyi. (2016). Intelligent fault diagnosis in a power distribution network. Advances in Electrical Engineering. 1-11.

[15] Oluseyi, P. O., Adelaja, T. S. and Akinbulire, T. O. (2017). Analysis of the transient stability limit of Nigeria's 330kV transmission sub-network. Nigerian Journal of Technology (NIJOTECH), 36(1); 213 226.

[16] Olusuyi, K., Oluwole, A. S., Adefarati, T. and Babarinde, A. K. (2014). A fault analysis of $11 \mathrm{kv}$ distribution system (a case study of Ado Ekiti electrical power distribution district). American Journal of Electrical Power and Energy Systems 3(2): 27-36.

[17] Onohaebi, O. S. (2009). Power outages in Nigeria Transmission grid. Research Journal of Applied Sciences, 4(1): 1-9.

[18] Osahenvemwen, A. O and Omorogiuwa, O. (2008). Electric power transmission line faults in Nigeria: a case study of Benni-Irrua $132 \mathrm{kV}$ transmission line. International Journal of Electrical and Power Engineering, 2(6): 384-388.

[19] Oyetunji, S. A. (2013). Development and implementation of faults location algorithm with graphic user interface (GUI) in radial electric power distribution network in Nigeria. International Journal of Engineering and Innovative Technology, 2(11): 83-89.

[20] Samuel, I. A., Awelewa, A. A., Katende, J. and Odigwe, I. A. (2013). Fault tree-based reliability assessment of a 132-kV transmission line protection scheme. American Journal of Engineering Research, 02 (10): 100-106.

[21] Shalangwa, D. A., Shinggu, D. Y. and Jonathan, T. (2009). An analysis of electric power faults in Mubi undertaking station, Adamawa state, Nigeria. The Pacific Journal of Science and Technology, 10 (2): 508-513. 